\title{
Predator-Prey Coevolution Drives Productivity-Richness Relationships in Planktonic Systems
}

\author{
Zhichao $\mathrm{Pu}^{1, *}$ Michael H. Cortez, ${ }^{2}$ and Lin Jiang ${ }^{1, \dagger}$ \\ 1. School of Biological Sciences, Georgia Institute of Technology, Atlanta, Georgia 30332; 2. Department of Mathematics and Statistics, \\ Utah State University, Logan, Utah 84322
}

Submitted February 15, 2016; Accepted September 14, 2016; Electronically published November 23, 2016

Online enhancements: appendixes.

\begin{abstract}
A вSTRACт: The relationship between environmental productivity and species richness often varies among empirical studies, and despite much research, simple explanations for this phenomenon remain elusive. We investigated how phytoplankton and zooplankton coevolution shapes productivity-richness relationships in both phytoplankton and zooplankton, using a simple nutrient-phytoplankton-zooplankton model that incorporates size-dependent metabolic rates summarized from empirical studies. The model allowed comparisons of evolved species richness across productivity levels and at different evolutionary times. Our results show that disruptive selection leads to evolutionary branching of phytoplankton and zooplankton. Both the time required for evolutionary branching and the number of evolved species in phytoplankton and zooplankton tend to increase with productivity, producing a transient unimodal or positive productivity-richness relationship but followed by a positive productivity-richness relationship for both groups over long enough evolutionary time. Our findings suggest that coevolution between phytoplankton and zooplankton can drive the two common forms (unimodal and positive) of productivity-richness relationships in nature.
\end{abstract}

Keywords: adaptive dynamics, evolutionary branching, nutrientphytoplankton-zooplankton (NPZ) model, predation, productivity, species diversity.

\section{Introduction}

A fundamental question in community ecology is how the number of species in a habitat relates to environmental productivity. This seemingly simple question has inspired numerous empirical investigations that have documented various forms of productivity-richness relationships (PRRs; e.g., Waide et al. 1999; Mittelbach et al. 2001; Gillman and Wright 2006; Gurevitch and Mengersen 2010; Hillebrand and Cardinale 2010). Positive and unimodal PRRs (e.g., fig. 1), in

\footnotetext{
* Deceased.

† Corresponding author; e-mail: lin.jiang@biology.gatech.edu. ORCIDs: Pu, http://orcid.org/0000-0001-6734-9088; Jiang, http://orcid.org 10000-0002-7114-0794

Am. Nat. 2017. Vol. 189, pp. 28-42. (C) 2016 by The University of Chicago. 0003-0147/2017/18901-56799\$15.00. All rights reserved.

DOI: $10.1086 / 689550$
}

general, are the two commonly observed patterns (Mittelbach et al. 2001; Gillman and Wright 2006) and have attracted the most attention. Consistent with these general patterns, extensive evidence in freshwater and marine planktonic systems often finds unimodal or positive PRRs on the regional scale (Dodson et al. 2000; Irigoien et al. 2004; Ptacnik et al. 2008; Korhonen et al. 2011; Stomp et al. 2011; app. A; apps. A$\mathrm{E}$ available online), although the response of species richness to productivity can vary on the local scale. To date, many factors are predicted to affect species richness along the productivity gradient, including predation (Leibold 1996), light condition (Huisman et al. 2004), resource ratio (Cardinale et al. 2009b), and ecosystem size (Stomp et al. 2011). However, a comprehensive understanding toward the mechanistic basis of the various PRRs is still lacking.

A host of hypotheses have been proposed to explain the observed PRRs (e.g., Wright 1983; Rosenzweig and Abramsky 1993; Tilman and Pacala 1993; Leibold 1998; Pärtel et al. 2007), mostly focusing on processes operating on ecological timescales (typically involving competition). While these hypotheses have helped us gain considerable insight into some of the ecological mechanisms regulating species richness along productivity gradients, they do not consider the possibility that evolutionary processes may also contribute to PRRs observed in various communities. Some studies have explored how evolutionary processes shape PRRs (Hochberg and van Baalen 1998; Jansen and Mulder 1999; Pärtel et al. 2007). For example, based on the rationale that habitat evolutionary history may affect PRRs through its influence on the size of the species pool, Pärtel et al. (2007) suggested that the paucity and short evolutionary history of productive habitats are responsible for the unimodal PRRs commonly found in temperate plant communities. Nevertheless, studies relating evolution to PRRs are scarce, and the question of how evolutionary time and environmental productivity combine to influence species richness (Pärtel et al. 2007; Zobel and Pärtel 2008), in particular, remains largely unanswered.

To address the above question, we examined the influence of evolutionary processes on PRRs in phytoplankton- 

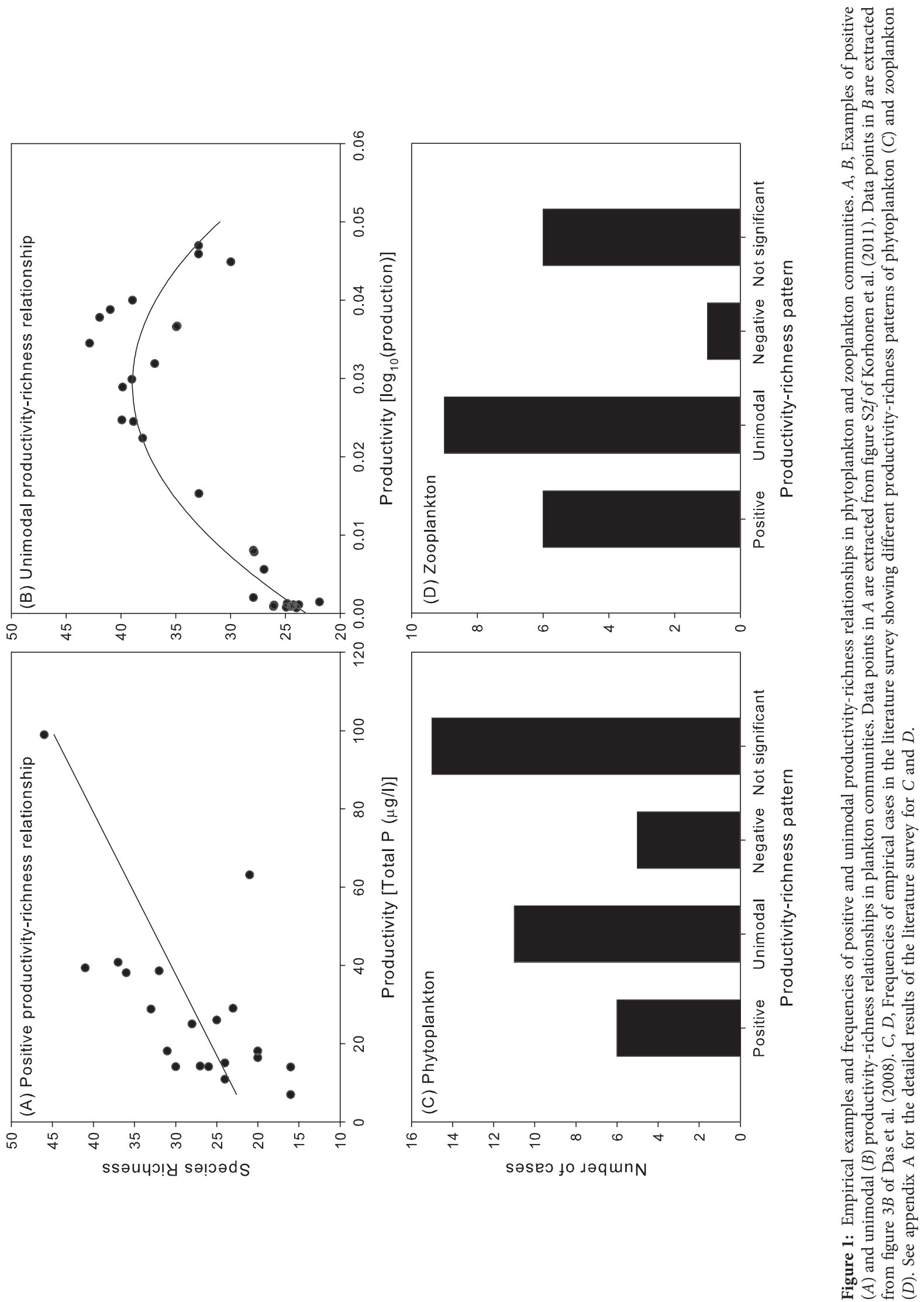

This content downloaded from 129.123.127.004 on January 25, 2017 11:06:01 AM 
zooplankton communities. We explored how phytoplanktonzooplankton coevolution influences species richness along a productivity gradient by using a simple nutrient-phytoplanktonzooplankton (NPZ) model. Taking advantage of the extensive work on metabolic rates and functional responses in planktonic organisms, we incorporated body-size-dependent population growth and trophic interactions into the evolutionary NPZ model. Body size was the focal trait in our model that dictated the fitness of phytoplankton and zooplankton populations. Using the theory of adaptive dynamics (Dieckmann and Law 1996; Geritz et al. 1998; Doebeli and Dieckmann 2000), we investigated plankton evolutionary dynamics through the analysis of evolutionary singular strategies and numerical simulations. The analyses allowed us to explore temporally evolved species richness at a given level of productivity as well as compare species richness across productivity levels at a given evolutionary time.

\section{NPZ Model and Methods}

\section{Ecological Component of the NPZ Model}

To study how coevolution affects phytoplankton and zooplankton PRRs, we developed a simple NPZ model based on the one used by Jiang et al. (2005) that explored the adaptive evolution of body size in zooplankton and phytoplankton. Similar to traditional NPZ models, the ecological component of our model describes the dynamics of three variables: nutrient concentration $(N)$, phytoplankton density $(P)$, and zooplankton density $(Z)$. As a first approach to studying the effects of evolutionary processes on PRRs, we do not consider how other abiotic variables (e.g., temperature) influence phytoplankton growth. We characterized phytoplankton populations by two key parameters, population densities $(P)$ and cell size $(x)$. Similarly, $Z$ and $y$ represent zooplankton population density and body size, respectively. The ecological component of the model is

$$
\begin{aligned}
& \frac{d N}{d t}=I-d N-\mu(x) g(N) P Q(x)+\gamma B(P, Z, x, y), \\
& \frac{d P}{d t}=P[\mu(x) g(N)-m-s(x)-C(x, y) Z], \\
& \frac{d Z}{d t}=Z\left[\phi \frac{Q(x)}{q(y)} C(x, y) P-\delta\right] .
\end{aligned}
$$

All model parameters and functions are defined in table 1. The amount of nutrient $N$ is determined by the nutrient supply rate $I$ (i.e., the measure of environmental productivity); nutrient loss (due to outflow) proportional to $N$; uptake by phytoplankton $\mu(x) g(N) P Q(x)$, which depends on the phy- toplankton nutrient quota $Q(x)$; and nutrient recycling $\gamma B(P, Z)$. The dynamics of the phytoplankton population are determined by four processes: a size-dependent nutrient uptake rate $\mu(x) g(N)$; mortality due to a constant size-independent per capita mortality rate $m$ and a size-dependent per capita sinking rate $s(x)$; and a size-dependent zooplankton consumption rate $C(x, y)$. The dynamics of the zooplankton population are determined by a size-independent per capita mortality rate $\delta$ and the rate of consumption and assimilation of phytoplankton biomass, which depends on a size-dependent consumption rate $C(x, y)$; the size-dependent nutrient quota of the phytoplankton $Q(x)$; the size-dependent nutrient quota of the zooplankton $q(y)$; and the size-independent assimilation efficiency of the zooplankton $\phi$. The rate of nutrient recycling is $\gamma B(P, Z, x, y)=\gamma[m Q(x) P+\delta q(y) Z+(1-\phi)$ $Q(x) C(x, y) P Z]$, where $\gamma$ is the proportion of recycled nutrient loss; $B(P, Z)$ is the total nutrient loss in detritus, including the death of phytoplankton, the death of zooplankton, and phytoplankton consumption.

We use the nutrient supply rate $I$ to represent environmental productivity for two reasons. First, the primary productivity usually estimated by chlorophyll $a$ or phytoplankton biomass is not a direct measure of resource supply or the rate of resource supply but is itself an ecosystem function of phytoplankton, which usually correlates with environmental resource supply (Cardinale et al. 2009a). Thus, the relationship between primary productivity and phytoplankton richness in our model would be a richness-productivity relationship rather than a causal productivity-richness relationship. Second, the primary productivity in our model is subject to change during the phytoplankton-zooplankton coevolution even if the resource supply remains constant. Manipulating primary productivity can implicitly affect coevolution dynamics in the model. Instead, the abiotic nutrient supply $I$ would be an unequivocal indicator of resource supply (i.e., environmental productivity).

The function $\mu(x)$ describes how the maximum phytoplankton growth rate depends on phytoplankton cell size. Empirical observations suggest that the scaling relationship between phytoplankton growth rate and cell size is not monotonic. Nielsen (2006) suggested that growth rates of unicellular green algae and cyanobacteria decrease with cell sizes, following a power function with the exponent ranging from $-1 / 3$ to $-1 / 4$. At smaller cell sizes, however, picoplankton showed a positive or unimodal scaling relationship (Raven 1994; Bec et al. 2008). By using different phyla of marine phytoplankton, Marañón et al. (2013) showed a unimodal size scaling relationship of phytoplankton growth. Therefore, phytoplankton growth rate is likely a unimodal function of cell size along a wide range of cell sizes. In addition, mechanistic models involving size-dependent catalytic limitation and resource uptake kinetics also find a unimodal relationship between growth rates and cell size (Verdy et al. 
Table 1: Definitions and units of parameters and functions in the model (eqq. [1a]-[1c])

\begin{tabular}{|c|c|c|}
\hline Parameter/function & Definition & Unit \\
\hline$N$ & Nutrient concentration & $\mu \mathrm{mol} / \mathrm{L}$ \\
\hline$P$ & Phytoplankton density & $10^{8}$ cells $/ \mathrm{L}$ \\
\hline$Z$ & Zooplankton density & $10^{6}$ individual $/ \mathrm{L}$ \\
\hline$x$ & Phytoplankton cell size (estimated spherical diameters [ESD]) & $\mu \mathrm{m}$ \\
\hline$y$ & Zooplankton cell size (ESD) & $\mu \mathrm{m}$ \\
\hline$I$ & Nutrient inflow rate ${ }^{\mathrm{a}}$ & $\mu \mathrm{mol} / \mathrm{L} / \mathrm{day}$ \\
\hline$d$ & Nutrient outflow rate & $1 /$ day \\
\hline$\mu(x)=\frac{x}{c_{1}^{2}+c_{x} x+c}$ & Maximum phytoplankton growth rate & $1 /$ day \\
\hline$\left(c_{1}, c_{2}, c_{3}\right)^{c_{1} x_{2}+c_{2} x+c_{3}}$ & Coefficients of $\mu(x)$ & $\left(1 / \mu \mathrm{m}^{2}, 1 / \mu \mathrm{m}\right.$, unitless $)$ \\
\hline$g(N)=\frac{N}{N+K}$ & Nutrient limitation for phytoplankton growth & Unitless \\
\hline K & Half-saturation constant & $\mu \mathrm{mol} / \mathrm{L}$ \\
\hline$Q(x)=\beta x^{b_{1}}$ & Phytoplankton nutrient quota & $\mu \mathrm{mol} / 10^{8}$ cells \\
\hline$\beta$ & Phytoplankton nutrient quota coefficient & $\mu \mathrm{mol}$ nutrient $/ \mathrm{cell} / \mu \mathrm{m}^{-b_{1}}$ \\
\hline$b_{1}$ & Phytoplankton nutrient quota exponent & Unitless \\
\hline$\gamma$ & Proportion of recycled detritus & Unitless \\
\hline$m$ & Size-independent per capita phytoplankton mortality rate & $1 /$ day \\
\hline$s(x)=\alpha x^{2}$ & Phytoplankton sinking rate ${ }^{\mathrm{b}}$ & 1/day \\
\hline$\alpha$ & Sinking rate coefficient & $1 /$ day $/ \mu \mathrm{m}^{2}$ \\
\hline$C(x, y)=C_{m} \exp \left[-\frac{1}{\lambda}(x-\theta y)^{2}\right]$ & Zooplankton consumption rate & $\mathrm{L} / 10^{6}$ individual/day \\
\hline$C_{\mathrm{m}}$ & Maximum consumption rate & $\mathrm{L} /$ day \\
\hline$\lambda$ & Consumption rate coefficient & $\mu \mathrm{m}^{2}$ \\
\hline$\theta$ & Consumption rate coefficient & Unitless \\
\hline$\phi$ & Consumption assimilation efficiency & Individual/cells \\
\hline$q(y)=\rho y^{b_{2}}$ & Zooplankton nutrient quota & $\mu \mathrm{mol} / 10^{6}$ individual \\
\hline$\rho$ & Zooplankton nutrient quota coefficient & $\mu \mathrm{mol}$ nutrient/individual $/ \mu \mathrm{m}^{-b}$ \\
\hline$b_{2}$ & Zooplankton nutrient quota exponent & Unitless \\
\hline$\delta$ & Size-independent per capita zooplankton mortality rate & 1/day \\
\hline
\end{tabular}

Note: See appendix C for the estimates of parameter values from empirical studies. ESD = estimated spherical diameters.

a The nutrient inflow rate $I$ is used as a measure of environmental productivity in this article.

b The phytoplankton sinking rate $s(x)$ is based on the Stokes equation.

2009; Wirtz 2011). Here we define the scaling relationship between phytoplankton growth rate and cell size by

$$
\mu(x)=\frac{x}{c_{1} x^{2}+c_{2} x+c_{3}},
$$

where the constants $c_{1}, c_{2}$, and $c_{3}$ are chosen so that the shape of $\mu(x)$ satisfies the conditions

$$
\left\{\begin{array}{ll}
\mu^{\prime}(x)>0 ; \mu^{\prime \prime}(x)<0 & \text { small } x \\
\mu^{\prime}(x)<0 ; \mu^{\prime \prime}(x)>0 & \text { large } x
\end{array} .\right.
$$

We examine different unimodal shapes of $\mu(x)$ by varying values of $c_{1}, c_{2}$, and $c_{3}$ (see "Results" for details).

Empirical evidence suggests that zooplankton consumption rates are maximized when zooplankton feed on particles with an optimal predator-prey size ratio, although the size ratio may vary across species (e.g., Hansen et al. 1994). Thus, we formulated $C(x, y)$ as

$$
C(x, y)=C_{m} \exp \left[-\frac{1}{\lambda}(x-\theta y)^{2}\right],
$$

where the maximum consumption rate $C_{m}$ occurs when zooplankton encounter phytoplankton at the optimal predatorprey ratio $\theta$. The consumption rate decreases from $C_{m}$ with an exponential rate $1 / \lambda$ when the phytoplankton size $x$ deviates from the optimal prey size $\theta y$.

\section{Evolutionary Component of the NPZ Model}

We assume there is heritable genetic variation in the body sizes of the phytoplankton and zooplankton. We further assume that the genetic variation is small enough that the evolutionary dynamics of body size can be modeled using the theory of adaptive dynamics (Dieckmann and Law 1996; Geritz et al. 1998; Doebeli and Dieckmann 2000). In this framework, the ecological dynamics of the system (e.g., changes in population sizes) are much faster than the evolutionary changes in mean body size within the populations. Note that whereas a population may require multiple generations to reach an ecological equilibrium, this framework assumes no mutation during the transient period of ecological dynamics. Thus, the generation time of a spe- 
cies does not affect evolutionary dynamics in our model system.

In the adaptive dynamics framework, the rate of change of each mean trait value is determined by the product of the species' mutation rate, its population size, and the individual fitness gradient:

$$
\begin{aligned}
& \frac{d x}{d t}=\left.M_{1} P^{*} \frac{\partial}{\partial x_{1}} F\left(x_{1}, x, y\right)\right|_{x_{1}=x}, \\
& \frac{d y}{d t}=\left.M_{2} Z^{*} \frac{\partial}{\partial y_{1}} G\left(y_{1}, x, y\right)\right|_{y_{1}=y},
\end{aligned}
$$

where $M_{1}$ and $M_{2}$ are the respective mutation rates of the phytoplankton and the zooplankton. The mean trait values of the resident phytoplankton and zooplankton populations are $x$ and $y$, respectively. When the resident densities are at equilibrium, $\left(N^{*}, P^{*}, Z^{*}\right)$, the fitness of a mutant phytoplankton with trait $x_{1}$ is $F\left(x_{1}, x, y\right)$, and the fitness of a mutant zooplankton with trait $y_{1}$ is $G\left(y_{1}, x, y\right)$. The fitness functions for the mutants are

$$
\begin{aligned}
& F\left(x_{1}, x, y\right)=\mu\left(x_{1}\right) g\left(N^{*}\right)-s\left(x_{1}\right)-m-C\left(x_{1}, y\right) Z^{*}, \\
& G\left(y_{1}, x, y\right)=\phi P^{*} Q(x) \frac{C\left(x, y_{1}\right)}{q\left(y_{1}\right)}-\delta .
\end{aligned}
$$

\section{Analytical Analysis}

We are interested in the conditions that lead to diversification (i.e., speciation or evolutionary divergence) within the phytoplankton and zooplankton populations. A system with monomorphic phytoplankton and zooplankton populations converges to an evolutionary singular strategy (i.e., equilibrium) that satisfies

$$
\begin{aligned}
& 0=\left.\frac{\partial}{\partial x_{1}} F\left(x_{1}, x, y\right)\right|_{x_{1}=x}, \\
& 0=\left.\frac{\partial}{\partial y_{1}} G\left(y_{1}, x, y\right)\right|_{y_{1}=x} .
\end{aligned}
$$

At the evolutionary singular points, evolutionary branching occurs in the phytoplankton population when $\partial^{2} F /\left.\partial x_{1}{ }^{2}\right|_{x_{1}}={ }_{x}>0$ and in the zooplankton population when $\partial^{2} G /\left.\partial y_{1}{ }^{2}\right|_{y_{1}}=y>0$ (see app. B.2 for details).

Due to the complexity of the NPZ model, we perform analytical analysis on the special case where there is no nutrient recycling ( $\gamma=0$; app. B) to make predictions about species diversification. In particular, we explore the conditions for evolutionary diversification of the phytoplankton when the zooplankton are absent and the conditions for coevolutionary diversification of the phytoplankton and zooplankton. Notably, after diversification occurs in a monomorphic system, coevolution can lead to further adaptive radiation and speciation events. The increasing polymorphisms made it difficult to obtain analytical solutions of our model (e.g., McGill and Brown 2007). Hence, we examined further adaptive radiation of phytoplankton and zooplankton using numerical simulations.

\section{Numerical Simulations}

Our numerical simulations were done with nutrient recycling present $(\gamma>0)$. The simulation results would remain qualitatively unchanged if there were no nutrient cycling, given that nutrient recycling essentially results in higher equilibrium nutrient concentrations, equivalent to higher influx rates. The body sizes for the phytoplankton and zooplankton populations were discretized into bins with widths of $0.1 \mu \mathrm{m}$ and $0.2 \mu \mathrm{m}$, respectively. We chose $0.1 \mu \mathrm{m}$ for the phytoplankton size classes because they are small enough that many size classes fall within the assumed distribution for zooplankton predation, $C(x, y)$, for a fixed zooplankton size, $y$. We chose $0.2 \mu \mathrm{m}$ for the zooplankton size classes simply for computational efficiency; because the value of $\theta$ (the optimal predator-prey body-size ratio) is less than 1 , we need larger values of the predator trait $(y)$, which requires many more size classes than is needed for the prey. The width of the size bins is small enough for the simulations to demonstrate varying population abundance and discontinuous size distributions of phytoplankton and zooplankton (e.g., fig. 2). Each simulation began with a single monomorphic population for each trophic level. The size bin of the initial monomorphic phytoplankton is determined by the evolutionarily stable strategy (ESS)-stable phytoplankton size in the absence of zooplankton (app. B.3), and the size bin of the initial monomorphic zooplankton is the associated optimal consumer size $(x / \theta)$. In the simulation, we generated the ecological dynamics of the model (eqq. [1a][1c]) for a fixed time interval (50 days) using ode45 in Matlab. We used the 50-day interval because it allowed us to capture transient patterns without accumulating too many mutants within each interval, which would otherwise obscure ecological dynamics. Further simulations with different time lengths showed qualitatively similar results as long as the time length was not extremely large (e.g., less than 10,000 days). At the end of the 50-day time period, the random number of mutant offspring that arose in each population was computed based on the per capita mutation rates $\left(M_{1}\right.$ and $M_{2}$ in eq. [5]) and then distributed into the adjacent size bins. These populations in all size bins were then used in the next round of ecological dynamics simulation. The simulated processes for generating ecological dynamics and mutants were repeated until the total length of time for the simulation reached 20,000 days. In our simulations, different combinations of per capita mutation rates of phytoplankton and zooplankton $\left(M_{1}\right.$ and $M_{2}$ in eq. [5]), ranging from $10^{-6}$ to $10^{-8}$, generated qualitatively similar results. Thus, we re- 

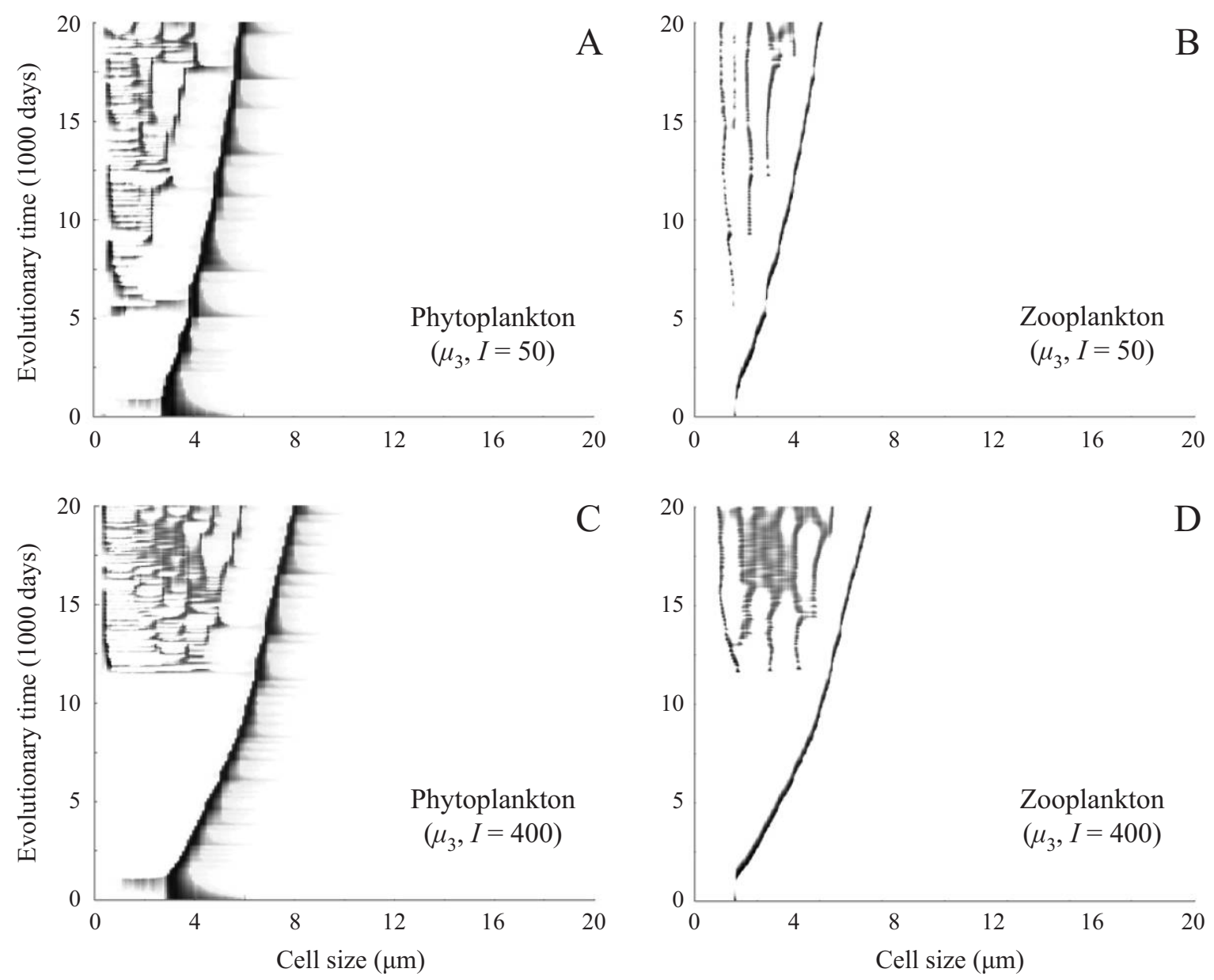

Figure 2: Examples of evolutionary diversification in phytoplankton $(A, C)$ and zooplankton populations $(B, D)$ for low $(A, B)$ and high $(C, D)$ productivity levels. The shades of black in the plots represent the relative (log-transformed) population abundances for the different cell sizes; darker shades mean higher density of a particular cell size at a specific time, lighter shades mean lower density, and white means absent zero density. For a specific evolutionary time, shading for multiple cell sizes implies the coexistence of multiple species with different cell sizes.

port only the results with mutation rates of $10^{-6}$ for both trophic levels in this article.

To assess PRRs in the simulated ecological and evolutionary processes, we ran simulations with seven different productivity levels $(I=20,50,100,150,200,300$, and $400 \mu \mathrm{mol}$ nutrient/L/day), mimicking the range of productivities observed in natural systems (see app. C for parameter values). As discussed in more detail in appendix B.4, evolutionary branching in the phytoplankton and zooplankton depends on the shape of $\mu(x)$. We thus ran simulations with six different parameterizations of $\mu(x)$ to explore potential evolutionary divergence under each scenario. In particular, $\mu_{1}-\mu_{4}$ are unimodal with different values for the parameters $c_{1}, c_{2}$, and $c_{3} ; \mu_{5}$ is monotonically increasing; and $\mu_{6}$ is monotonically decreasing (see fig. D1 in app. D; figs. D1, D2 available online). The parameters for $\mu_{1}-\mu_{4}$ were generated by randomly selecting values that yield functions that fall within the range of observed scaling relationships between plankton growth rates and cell size (for details, see app. C). Note that the observed scaling relationship of phytoplankton constrained the shape of the functions $\mu_{1}-\mu_{4}$ to be unimodal. We also ran simulations with a monotonically increasing and concave down function $\left(\mu_{5}\right)$ and a monotonically decreasing and concave up function ( $\mu_{6}$; fig. D1). Because the conditions for evolutionary branching of phytoplankton and zooplankton tend to be less sensitive to the changes in other parameter values (see app. B.4), we used a fixed set of values for other parameters in the simulations (fig. 3) that fall within the range of parameter values observed in empirical systems (app. C). Ten replicate runs were done for each combination of the seven productivity levels and six forms of $\mu(x)$, totaling 420 separate runs.

To assess species richness at different evolutionary times, we collected the following data from each simulation. We 


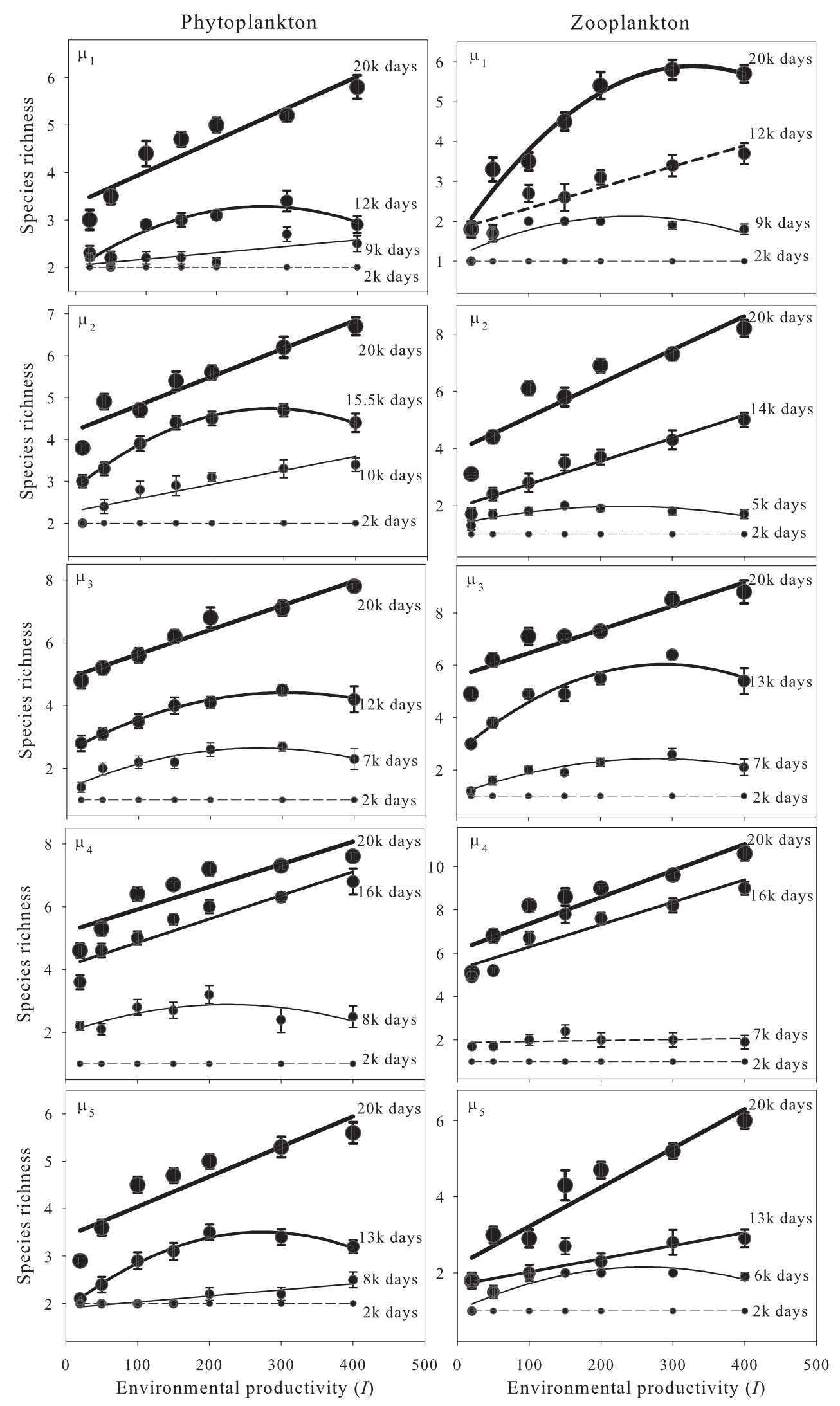

This content downloaded from 129.123.127.004 on January 25, 2017 11:06:01 AM All use subject to University of Chicago Press Terms and Conditions (http://www.journals.uchicago.edu/t-and-c). 
recorded the log-transformed abundances of phytoplankton and zooplankton in each size bin, every 500 days in the simulation, to generate size and abundance distributions for phytoplankton and zooplankton (fig. 2) at 40 evolutionary time points. At each evolutionary time point, a species was defined as a phenotypic cluster with similar cell sizes of phytoplankton or zooplankton. Note that this assumption precludes the possibility of taxonomic species having the same size distributions. The number of such phenotypic clusters (species richness) was estimated by univariate normal mixture analysis using the expectation-maximization algorithm implemented from the mixtools package (Benaglia et al. 2009) in R 3.0.3 (http://www.r-project.org). For a given number of phenotypic clusters $(n)$, the expectation-maximization algorithm searches for $n$ sets of parameters for normal distributions that best describe the populations with $n$ phenotypic clusters. The goodness of fit of different numbers of phenotypic clusters estimated by the expectation-maximization algorithm was then compared using the function boot.comp in the mixtools package. Species richness was assessed as the number of multiple normally distributed phenotypic clusters best fit for the simulated size and abundance distributions.

We assessed the shape of PRRs from our numerical simulations in two scenarios. In the first scenario, we compared species richness across productivity levels where all environments are equally old. This identifies how fast communities with different productively levels reach particular levels of species richness. At each evolutionary time point, we performed Mitchell-Olds and Shaw (MOS) tests (MitchellOlds and Shaw 1987) for the simulated species richness with each form of $\mu(x)$ along the productivity gradient by using the vegan package (Oksanen et al. 2013) in R. We considered the shape of PRRs as unimodal when the MOS tests suggested a significant quadratic hump (or pit) of species richness located within the range of the simulated environmental productivity. Otherwise, we considered the shape of PRRs as positive or negative when simple linear regressions showed significant relationships between productivity and species richness. PRRs were considered to have no clear trend (hereafter, no trend) if there were no significant results in MOS tests or simple linear regressions.
The results in the first scenario, however, are difficult to compare to the PRRs observed in empirical systems because the first scenario assumes that all environments have been around for the same amount of evolutionary time. A more appropriate comparison is to compare species richness across productivity levels where the evolutionary time for each productivity level is chosen randomly. In this second scenario, we chose a random point in time (day 0-day 20,000) for each productivity level and extracted species richness for phytoplankton and zooplankton. The shape of PRR was then determined by the MOS tests and linear regressions (positive, unimodal, negative, or no trend; see the first scenario above for details). We repeated the resampling 1,000 times, yielding 1,000 different PRRs of phytoplankton and zooplankton across environments with different evolutionary times. In addition, we also quantified the frequency, out of the 1,000 resampled PRRs, that coevolution generates the same type of PRRs in both phytoplankton and zooplankton populations.

In both scenarios above, the number of productivity levels and replicates can determine the effect sizes in the MOS tests and linear regressions and thus affect the $P$ values of the statistical tests. To avoid the possibility of arbitrarily high numbers of replications (or productivity levels) inflating the degrees of freedom used to produce significant statistical results (White et al. 2014), we chose seven productivity levels and 10 replicates so that the sample size of PRRs in our simulation (70 data points) were comparable to those in empirical studies (e.g., app. A). Adding more productivity levels or replications tends to reduce the frequency of no-trend PRRs but does not alter the relative frequency of positive, unimodal, or negative PRRs.

\section{Results}

Here we present the analytical results of the conditions for evolutionary diversification on a special case with no nutrient recycling $(\gamma=0)$ in the model system (eqq. [1a]-[1c]). All analytical analysis and results are presented in detail in appendix B. In the absence of zooplankton, phytoplankton

Figure 3: Examples of phytoplankton (left) and zooplankton (right) species richness across environmental productivity levels at the same evolutionary time points in the simulations. Species richness was estimated using the expectation-maximization algorithm (see "Numerical Simulations" for more details). Each row shows simulation results for one of the phytoplankton growth rates ( $\left.\mu_{1}-\mu_{5}\right)$. In each panel, a productivityrichness relationship (PRR) at a given evolutionary time is shown by a set of points with error bars and a regression line with the evolutionary time listed adjacent to the regression line; larger points and thicker regression lines indicate PRRs at a later evolutionary time. Each point represents the mean of species richness estimated at that productivity level. Shapes of regression lines (unimodal or linear) are determined by Mitchell-Olds and Shaw tests (see "Numerical Simulations" for details). Solid regression lines indicate significant PRRs, while dashed regression lines represent nonsignificant PRRs. For each panel, four different evolutionary time points were selected to demonstrate different PRRs across evolutionary time. Error bars indicate standard errors. Parameter values used in the simulations lie within the ranges estimated from empirical systems listed in appendix C: $\alpha=0.001, \beta=5.44 \times 10^{-9}, \rho=1.36 \times 10^{-9}, \gamma=0.1, \theta=0.5, \lambda=0.2, C_{m}=10^{-5}, m=0.071, \delta=0.05, K=2, \varphi=$ $0.1, d=0.01, M_{x}=M_{y}=10^{-6}$. The values of $c_{1}-c_{3}$ in $\mu(x)$ are as in figure D1. 
do not diversify regardless of the level of environmental productivity (app. B.3). When phytoplankton and zooplankton coexist, coevolutionary divergence in phytoplankton and zooplankton can be driven by diversification in the phytoplankton (which then causes diversification in the zooplankton) or by diversification in the zooplankton (which then causes diversification in the phytoplankton; app. B.4). Phytoplankton-driven divergence is likely to occur when the zooplankton have a nearly optimal size for consuming phytoplankton $(x=\theta y)$; the constant $\alpha$ in the phytoplankton sinking rate $s(x)$ is not too large; and phytoplankton have large cell sizes with positive enough $\mu^{\prime \prime}(x)$ or small cell sizes so that $\mu^{\prime \prime}(x)$ is smaller in magnitude compared to the value of $\left(\partial^{2} C / \partial x^{2}\right) Z^{*}$ (app. B.4). Zooplankton-driven divergence is likely to occur when the zooplankton consumption rate $C(x, y)$ is nearly linear at the evolutionary singular point $y$ and the nutrient quota $q(y)$ is nearly linear at $y$ (app. B.4). The first condition for zooplankton-driven divergence (linear consumption rate) is not likely to arise since it implies a suboptimal match between the zooplankton and phytoplankton cell sizes (i.e., zooplankton are much larger or smaller than the optimal size for consuming prey of size $x$ ). Thus, our results suggest that, in our system, coevolutionary diversification is more likely to be driven by diversification in the phytoplankton.

In agreement with our theoretical predictions (app. B.4), our numerical simulations of phytoplankton-zooplankton eco-evolutionary dynamics showed that speciation of either species did not occur when $\mu(x)$ is a monotonic decreasing function of body size $\left(\mu_{6}\right)$. Thus, we present only the simulation results for the five other functions of $\mu(x)\left(\mu_{1}-\mu_{5}\right)$. The results of species richness across productivity levels where environments are equally old are shown in figure 3 (see fig. 2 as an example of a particular simulation). The results in figure 3 show two kinds of PRRs at different evolutionary time points. First, for long evolutionary time, only positive PRRs are observed in both phytoplankton and zooplankton (except for zooplankton in $\mu_{1}$; for a summary of the shape of PRRs, see table D1 in app. D; tables A1, C1-C4, D1 available online). Second, for some intermediate evolutionary time points, unimodal PRRs are present in the simulations (table D1).

The unimodal and positive PRRs in figure 3 are difficult to match empirical observations (e.g., fig. 1) because environments with different productivity levels are not necessarily at the same evolutionary time in empirical systems. For a more appropriate comparison, we resampled our simulation data so that evolutionary time varied between environments. A large proportion of the PRRs obtained from the resampling were positive or unimodal for both phytoplankton (positive: 36.1\%-43.6\%; unimodal: 39.7\%-46.4\%; fig. $4 A$ ) and zooplankton (positive: $37.6 \%-45.5 \%$; unimodal: $40.9 \%-45.7 \%$; fig. $4 B$ ). These results suggest that positive and unimodal PRRs are typical outcomes of phytoplankton-zooplankton coevolution. The resampling results also showed that PRRs of phytoplankton and zooplankton resampled from the same set of environments are often of the same type (frequencies of same type of phytoplankton and zooplankton PRRs: $\mu_{1}$ : $80.4 \% ; \mu_{2}: 89.0 \% ; \mu_{3}: 92.8 \%$; $\mu_{4}: 91.9 \% ; \mu_{5}: 84.5 \%$ ).

Note that we observed similar PRRs in the numerical simulation with monotonic increasing $\mu(x)$ ( $\mu_{5}$; fig. 3; app. D). Hence, transient unimodal PRRs and positive PRRs over the long term do not require nutrient uptake rates to be unimodal functions of phytoplankton size. However, diversification did not occur with the monotonically decreasing function $\mu_{6}$, because under this situation the optimal trait value for phytoplankton is the smallest possible cell size (minimizing sinking mortality and predation), and the invasion by mutants with lower and higher trait values is not possible. Therefore, coevolutionary diversification can occur only if the nutrient uptake rate is an increasing function of cell size over some range of cell sizes.

\section{Discussion}

In our model, the coevolution of phytoplankton and zooplankton resulted in varied forms of PRRs (mostly unimodal and positive). Both unimodal and positive PRRs were observed in phytoplankton and zooplankton as transient phenomena, but only positive PRRs were likely observed given sufficient long periods of evolutionary time (fig. 3; table D1). The observed evolutionary dynamics were driven by two factors: resource competition among phytoplankton and predatorprey interactions between phytoplankton and zooplankton. In the absence of zooplankton, competition in phytoplankton followed the $R^{*}$ rule (Tilman 1982), resulting in a single population with the most competitive trait (app. B.3). The predator-prey interactions, on the other hand, may alter the fitness landscape of both trophic levels and lead to coevolutiondriven diversification. Our analytical results showed that this coevolutionary diversification is more likely driven by the diversification of phytoplankton (app. B.3). The evolutionary branching in phytoplankton, in turn, causes diversification in zooplankton. Similar to the findings in other studies on the evolution of food webs (Loeuille and Loreau 2005; Ito and Ikegami 2006), the simultaneous top-down and bottomup controls in our model system led to further diversification events in the phytoplankton and zooplankton trophic levels (e.g., fig. 2). It is this recursive diversification that produces similar PRRs for phytoplankton and zooplankton (fig. 3).

Our results showed that, when environments with different productivity levels have been around for the same evolutionary time, unimodal PRRs can arise at the intermediate evolutionary time as transient phenomena but would likely change into positive PRRs over long evolutionary time because of the higher species richness evolved at higher levels of productivity. We attribute the transient unimodal PRRs 

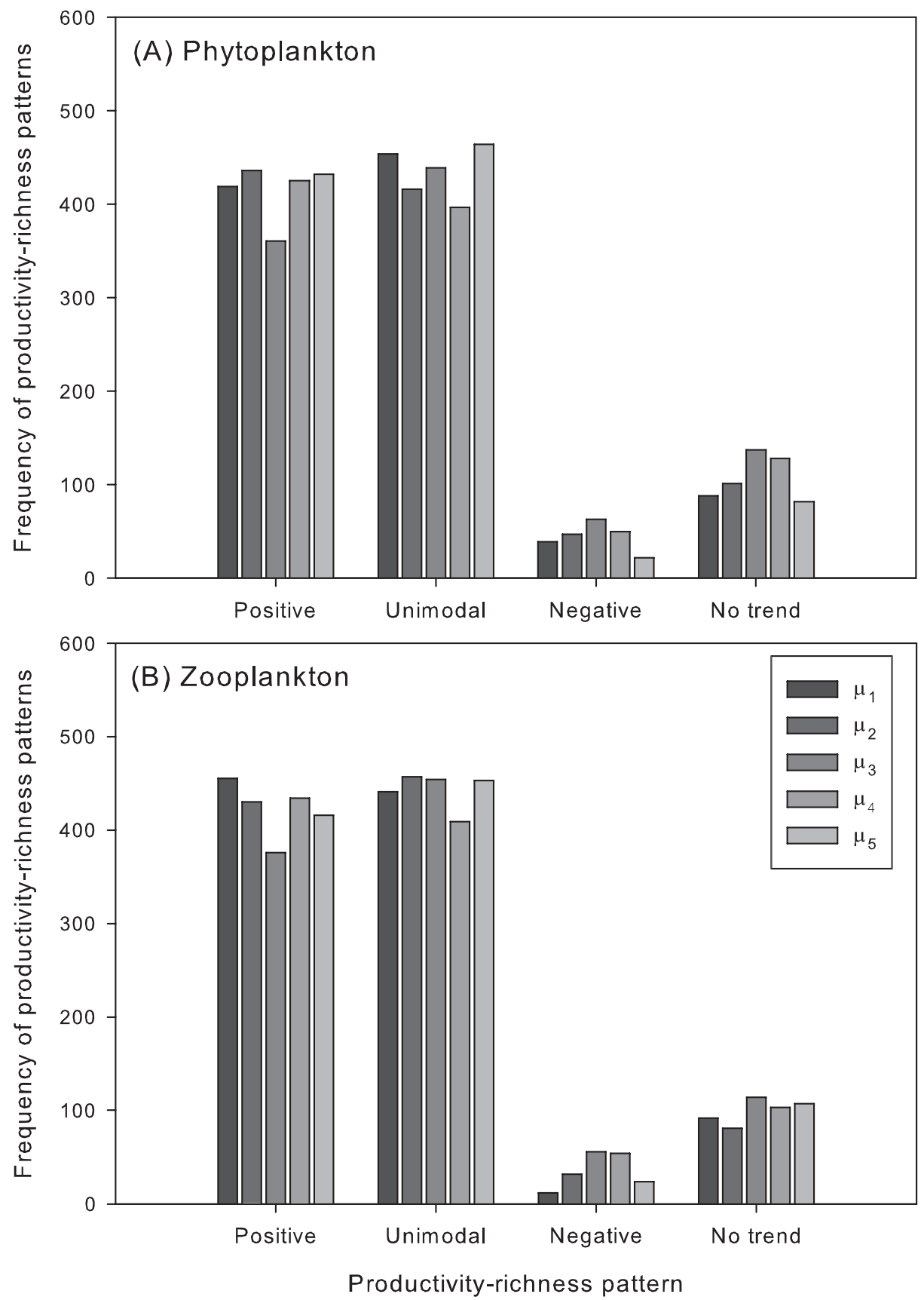

Figure 4: Frequencies of productivity-richness relationship (PRR) patterns of phytoplankton $(A)$ and zooplankton $(B)$ where evolutionary time differs between productivity levels. Species richness at each productivity level was estimated by randomly sampling species richness across evolutionary time points. Bars show the frequencies of each PRR pattern from 1,000 resamples. The PRR shape was determined using Mitchell-Olds and Shaw tests and simple linear regressions, and categorized into four possible forms (positive, negative, unimodal, and no trend).

in our model to the slow tempo of evolution at high levels of productivity. Specifically, while more species may coexist at higher productivities, the higher resident population densities that occur with higher productivities increase the time it takes for competitively superior mutants to replace the residents (e.g., fig. 2). The combination of the decreasing tempo of evolution and the increasing steady-state PRRs thus combine to produce unimodal transient PRRs. Taken together, our model predicts nonsignificant PRRs across newly formed communities, an increasing saturating PRR 
across communities with long enough evolutionary time length, and transient unimodal or positive PRRs of intermediate age (fig. 3; table D1). Consistent with our predictions, paleoecological evidence suggests that increase of marine phytoplankton (and zooplankton) richness in the Cambrian and the Ordovician is likely due to the increased nutrient availability (e.g., Servais et al. 2008, 2010). The diversification of oceanic phytoplankton in the Cambrian and the Ordovician was coupled with the diversification of zooplankton (Tappan and Loeblich 1973; Moczydłowska 2002; Servais et al. 2008; but see Vecoli and Le Hérissé 2004), also indicating the important role of predator-prey coevolution as emphasized in our model.

Directly comparing our model predictions where environments are equally old (fig. 3; table D1) to empirical data may not be entirely appropriate, as evolutionary time could vary among environments in empirical systems. As such, it is meaningful to examine predictions where evolutionary time is nonequal across environments with different productivity levels. Resampling across different evolutionary times showed that unimodal and positive PRRs are the two most commonly observed PRRs (fig. 4). These two forms of PRRs, again, arose from the combined influence of positive steady-state PRRs and the decreasing tempo of evolution at higher productivities. The increasing number of evolved species with productivity contributes to the increasing phase of unimodal PRRs and positive PRRs. On the other hand, the decreasing tempo of evolution with productivity results in a substantial chance for transient low richness from being resampled, leading to the decreasing phase of unimodal PRRs.

Compared to empirical evidence (fig. 1), negative PRRs were observed less frequently in our simulations (see fig. 4). This suggests that mechanisms (e.g., opportunist prey blooming before being consumed by predators in environments with strong seasonality; Vallina et al. 2014) other than phytoplankton-zooplankton coevolution may be important for negative PRRs in empirical systems. Nevertheless, our numerical simulations suggest the phytoplankton-zooplankton coevolution as a potential mechanism contributing to the unimodal and positive forms of PRRs observed in aquatic systems (e.g., fig. 1). Furthermore, the resampling results showed that coevolution likely leads to similar shapes of PRRs for phytoplankton and zooplankton, a pattern that needs further exploration beyond the few existing empirical studies on the topic (e.g., Leibold 1999; Dodson et al. 2000). Our simulations also suggest that as the evolutionary time increases, positive PRRs would be more common than unimodal PRRs, a prediction consistent with the observation for plants in temperate and tropic regions (Pärtel et al. 2007).

The prediction of evolving PRRs in our model may also help explain contemporary PRRs at different spatial scales. In a numerical sense, the scenario of a rare mutant establishing in an evolving community is analogous to the sce- nario of a rare immigrant species establishing in community assembly. Thus, interpreting our results in terms of contemporary PRRs yields the prediction of unimodal to positive PRRs mediated by predator-prey interactions at early stages of community assembly and positive PRRs at later stages of community assembly. On the regional scale, larger spatial extent is more likely to involve productive habitats with a longer history of community assembly. This results in positive saturating (or unimodal) regional PRRs, as frequently observed in lake or ocean plankton communities (e.g., Dodson et al. 2000; Irigoien et al. 2004; Korhonen et al. 2011; Stomp et al. 2011). Note that our study has focused only on evolving richness from monomorphic populations via small mutation steps, analogous to immigrant species with small trait difference to resident species. Immigration in community assembly, however, could also introduce immigrants with large trait difference. Future research should investigate the combined effects of evolutionary and ecological processes on ecological communities.

Our model also makes predictions about the evolutionary emergence of plankton body sizes. The average size of plankton in the steady-state PRRs increases with productivity in our simulations (fig. D2 in app. D), which is consistent with empirical patterns of marine phytoplankton (Irigoien et al. 2004). Considering the reduced evolution rate with increasing productivity, large cell sizes at high productivity levels are expected to evolve later. This prediction agrees with the fact that phytoplankton and zooplankton with larger body size recovered much more slowly after the end-Cretaceous mass extinction (Finkel 2007). In our model, the steady-state distribution of evolved plankton body sizes is characterized by regularly spaced coexisting sizes (e.g., fig. 2). The spaced size distribution is similar to the size structure found in estuarine phytoplankton (Segura et al. 2013). The discontinuous size distribution in our study is most likely driven by predatorprey coevolution, consistent with the pattern found in a recent NPZ model, which also considers size-dependent trophic interactions (Banas 2011). Notably, our prediction does not necessarily contradict with the smooth size distribution commonly expected in the planktonic system. Large spatial extent would consist of various evolving communities with different evolutionary history and steady-state size distribution, as expected in our model. The size variation across these communities can combine to result in a continuous size distribution on a large spatial scale. On the other hand, plankton communities indeed show discontinuous cell size distributions in freshwater lakes (Havlicek and Carpenter 2001) and marine ecosystems (Vergnon et al. 2009; Segura et al. 2013).

Despite the many consistencies between our predictions and empirical evidence, definitive empirical evidence that directly supports our predictions is difficult to obtain because of the evolutionary timescale considered in our study. In addition, the model that we used to explore predator-prey co- 
evolution is rather simple. For example, we assessed species richness as the number of morph species based on size structures of phytoplankton and zooplankton. Thus, species richness in our model results can be lower than the observed richness of taxonomic species because one size cluster may pack multiple taxonomic species in natural planktonic systems (e.g., Havlicek and Carpenter 2001; Segura et al 2013). However, our measure of species richness can better demonstrate the consequences of disruptive selection and diversification and are closely related to the concept of functional diversity. We also assumed simple resource competition in phytoplankton with one limiting resource that leads to a monomorphic phytoplankton population in the absence of zooplankton; it is possible that adding trade-offs in competition (e.g., Jansen and Mulder 1999; Smith et al. 2011) may influence the shape of PRRs. Nevertheless, the unequivocal demonstration of such trade-offs remains elusive. In addition, we assumed constant mortality rate for phytoplankton and zooplankton in the model. However, our analytical results (app. B.4) suggest that our results will hold if the assumptions on these parameters are relaxed. In particular, the presence of planktivorous fish can reduce mean cell sizes of the standing zooplankton populations through predation (Brucet et al. 2010). This influence of fish can cause a decelerating relationship between zooplankton mortality rate and zooplankton size that, in turn, facilitates zooplankton-driven divergence (app. B.4).

Another issue in our study is that we used a specific function $\mu(x)$ to describe the scaling relationship between phytoplankton growth rate and cell size and tested the PRRs with different shapes of $\mu(x)$ with parameter values falling within the range of observed patterns of the scaling relationship (app. C). A more mechanistic model for phytoplankton growth (e.g., Droop 1973; Verdy et al. 2009) would generate similar size scaling relationships under particular conditions (see details in app. E). Thus, we expect that our conclusion is unlikely to change if more mechanistic models are used to describe phytoplankton growth.

A third issue is that our model, which was based on the theory of adaptive dynamics, assumes ecological equilibria prior to evolutionary changes. There is increasing empirical evidence, however, that ecological and evolutionary dynamics could operate on the same timescales (Hairston et al. 2005; Fussmann et al. 2007; Hiltunen et al. 2014); such ecoevolutionary dynamics are also known for phytoplanktonzooplankton interactions (e.g., Yoshida et al. 2003). Speeding up the rate of evolution, however, will not affect our long-term result of positive PDRs, because we ran the simulations long enough that the system effectively reached an evolutionary equilibrium, and changing the speed of the evolutionary dynamics does not affect the equilibrium state. By contrast, it is not entirely clear how speeding up the rate of evolution will affect the transient dynamics of the system. In some cases, speeding up the rate of evolution will likely cause the unimodal PDRs to disappear; this would occur when increased evolutionary speed causes evolutionary branching to occur faster for higher productivity systems. On the other hand, speeding up the rate of evolution may not affect the transient PDRs if the increased speed affects all levels of productivity equally. We note that resolving this uncertainty, which is beyond the scope of the present study, warrants attention from future work.

Our results demonstrate that differences in evolutionary time can lead to different PRRs for coevolving phytoplankton and zooplankton. While our model was developed with the planktonic system in mind, we believe that our results may also apply to other systems, given that a variety of ecological interactions can lead to evolutionary branching (Doebeli and Dieckmann 2000) and that the general mechanisms driving PRRs in our model (e.g., slow tempo of evolution at high productivities) may similarly operate in other systems (e.g., plant communities; Pärtel et al. 2007). If confirmed, differences in evolutionary time may provide a simple explanation for the coexistence of the two most common PRRs observed in a variety of ecological communities.

\section{Acknowledgments}

We thank H. Wang and J. Weitz for advice on algorithm design and programming and W. Ryberg and J. Tan for critical reading of the manuscript. This project is supported by the National Science Foundation (DEB-1120281, DEB-1257858, DEB-1342754, and DMS-1204401) and the National Natural Science Foundation of China (NSFC 31361123001).

In memoriam: Dr. Zhichao Pu. We are saddened to report that Dr. Zhichao Pu (1983-2016), the first author of this article, passed away on Thursday, August 11, 2016, in a swimming accident. Dr. Pu received his B.S. from Fudan University (Shanghai) in 2006 and his Ph.D. from Georgia Institute of Technology in 2015. His research focused on community ecology, using both theoretical and experimental approaches. He published 13 peer-reviewed articles (including this one).

\section{Literature Cited}

Banas, N. S. 2011. Adding complex trophic interactions to a sizespectral plankton model: emergent diversity patterns and limits on predictability. Ecological Modelling 222:2663-2675.

Bec, B., Y. Collos, A. Vaquer, D. Mouillot, and P. Souchu. 2008. Growth rate peaks at intermediate cell size in marine photosynthetic picoeukaryotes. Limnology and Oceanography 53:863-867.

Benaglia, T., D. Chauveau, D. Hunter, and D. Young. 2009. mixtools: an R package for analyzing finite mixture models. Journal of Statistical Software 32:1-29.

Brucet, S., D. Boix, X. D. Quintana, E. Jensen, L. W. Nathansen, C. Trochine, M. Meerhoff, S. Gascón, and E. Jeppesen. 2010. Factors influencing zooplankton size structure at contrasting temperatures in 
coastal shallow lakes: implications for effects of climate change. Limnology and Oceanography 55:1697-1711.

Cardinale, B. J., D. M. Bennett, C. E. Nelson, and K. Gross. 2009a. Does productivity drive diversity or vice versa? a test of the multivariate productivity-diversity hypothesis in streams. Ecology 90 1227-1241.

Cardinale, B. J., H. Hillebrand, W. S. Harpole, K. Gross, and R. Ptacnik. $2009 b$. Separating the influence of resource "availability" from resource "imbalance" on productivity-diversity relationships. Ecology Letters 12:475-487.

Das, B., R. Nordin, and A. Mazumder. 2008. Relationship between phytoplankton paleoproduction and diversity in contrasting trophic states. Aquatic Ecosystem Health and Management 11:78-90.

Dieckmann, U., and R. Law. 1996. The dynamical theory of coevolution: a derivation from stochastic ecological processes. Lournal of Mathematical Biology 34:579-612.

Dodson, S. I., S. E. Arnott, and K. L. Cottingham. 2000. The relationship in lake communities between primary productivity and species richness. Ecology 81:2662-2679.

Doebeli, M., and U. Dieckmann. 2000. Evolutionary branching and sympatric speciation caused by different types of ecological interactions. American Naturalist 156(suppl.):S77-S101.

Droop, M. R. 1973. Some thoughts on nutrient limitation in algae. Journal of Phycology 9:264-272.

Finkel, Z. V. 2007. Does phytoplankton cell size matter? the evolution of modern marine food webs. Pages 333-350 in P. G. Falkowski and A. H. Knoll, eds. Evolution of primary producers in the sea. Academic Press, San Diego, CA.

Fussmann, G. F., M. Loreau, and P. A. Abrams. 2007. Eco-evolutionary dynamics of communities and ecosystems. Functional Ecology 21 465-477.

Geritz, S. A. H., É. Kisdi, G. Meszéna, and J. A. J. Metz. 1998. Evolutionarily singular strategies and the adaptive growth and branching of the evolutionary tree. Evolutionary Ecology 12:35-57.

Gillman, L. N., and S. D. Wright. 2006. The influence of productivity on the species richness of plants: a critical assessment. Ecology 87: 1234-1243.

Gurevitch, J., and K. Mengersen. 2010. A statistical view of synthesizing patterns of species richness along productivity gradients: devils, forests, and trees. Ecology 91:2553-2560.

Hairston, N. G., S. P. Ellner, M. A. Geber, T. Yoshida, and J. A. Fox. 2005. Rapid evolution and the convergence of ecological and evolutionary time. Ecology Letters 8:1114-1127.

Hansen, B., P. K. Bjørnsen, and P. J. Hansen. 1994. The size ratio between planktonic predators and their prey. Limnology and Oceanography 39:395-403.

Havlicek, T. D., and S. R. Carpenter. 2001. Pelagic species size distributions in lakes: are they discontinuous? Limnology and Oceanography 46:1021-1033.

Hillebrand, H., and B. J. Cardinale. 2010. A critique for meta-analyses and the productivity-diversity relationship. Ecology 91:2545-2549.

Hiltunen, T., N. G. Hairston, G. Hooker, L. E. Jones, and S. P. Ellner. 2014. A newly discovered role of evolution in previously published consumer-resource dynamics. Ecology Letters 17:915-923.

Hochberg, M. E., and M. van Baalen. 1998. Antagonistic coevolution over productivity gradients. American Naturalist 152:620-634.

Huisman, J., J. Sharples, J. M. Stroom, P. M. Visser, W. E. A. Kardinaal, J. M. H. Verspagen, and B. Sommeijer. 2004. Changes in turbulent mixing shift competition for light between phytoplankton species. Ecology 85:2960-2970.
Irigoien, X., J. Huisman, and R. P. Harris. 2004. Global biodiversity patterns of marine phytoplankton and zooplankton. Nature 429: 863-867.

Ito, H. C., and T. Ikegami. 2006. Food-web formation with recursive evolutionary branching. Journal of Theoretical Biology 238:1-10.

Jansen, V. A. A., and G. S. E. E. Mulder. 1999. Evolving biodiversity. Ecology Letters 2:379-386.

Jiang, L., O. M. E. Schofield, and P. G. Falkowski. 2005. Adaptive evolution of phytoplankton cell size. American Naturalist 166:496505.

Korhonen, J. J., J. Wang, and J. Soininen. 2011. Productivity-diversity relationships in lake plankton communities. PLoS ONE 6:e22041.

Leibold, M. A. 1996. A graphical model of keystone predators in food webs: trophic regulation of abundance, incidence, and diversity patterns in communities. American Naturalist 147:784-812.

1998. Similarity and local co-existence of species in regional biotas. Evolutionary Ecology 12:95-110.

- 1999. Biodiversity and nutrient enrichment in pond plankton communities. Evolutionary Ecology Research 1:73-95.

Loeuille, N., and M. Loreau. 2005. Evolutionary emergence of sizestructured food webs. Proceedings of the National Academy of Sciences of the USA 102:5761-5766.

Marañón, E., P. Cermeño, D. C. López-Sandoval, T. Rodríguez-Ramos, C. Sobrino, M. Huete-Ortega, J. M. Blanco, and J. Rodríguez. 2013. Unimodal size scaling of phytoplankton growth and the size dependence of nutrient uptake and use. Ecology Letters 16:371379.

McGill, B. J., and J. S. Brown. 2007. Evolutionary game theory and adaptive dynamics of continuous traits. Annual Review of Ecology Evolution, and Systematics 38:403-435.

Mitchell-Olds, T., and R. G. Shaw. 1987. Regression analysis of natural selection: statistical inference and biological interpretation. Evolution 41:1149-1161.

Mittelbach, G. G., C. F. Steiner, S. M. Scheiner, K. L. Gross, H. L. Reynolds, R. B. Waide, M. R. Willig, S. I. Dodson, and L. Gough. 2001. What is the observed relationship between species richness and productivity? Ecology 82:2381-2396.

Moczydłowska, M. 2002. Early Cambrian phytoplankton diversification and appearance of trilobites in the Swedish Caledonides with implications for coupled evolutionary events between primary producers and consumers. Lethaia 35:191-214.

Nielsen, S. L. 2006. Size-dependent growth rates in eukaryotic and prokaryotic algae exemplified by green algae and cyanobacteria: comparisons between unicells and colonial growth forms. Lournal of Plankton Research 28:489-498.

Oksanen, J., F. G. Blanchet, R. Kindt, P. Legendre, P. R. Minchin, R. B. O'Hara, G. L. Simpson, et al. 2013. vegan: community ecology package. $\mathrm{R}$ package, version 2.0-10.

Pärtel, M., L. Laanisto, and M. Zobel. 2007. Contrasting plant productivity-diversity relationships across latitude: the role of evolutionary history. Ecology 88:1091-1097.

Ptacnik, R., L. Lepistö, E. Willén, P. Brettum, T. Andersen, S. Rekolainen, A. L. Solheim, et al. 2008. Quantitative responses of lake phytoplankton to eutrophication in Northern Europe. Aquatic Ecology 42:227-236.

Raven, J. A. 1994. Why are there no picoplanktonic $\mathrm{O}_{2}$ evolvers with volumes less than $10^{-19} \mathrm{M}^{3}$ ? Journal of Plankton Research 16:565580.

Rosenzweig, M. L., and Z. Abramsky. 1993. How are diversity and productivity related? Pages 52-65 in R. E. Ricklefs and D. Schluter, 
eds. Species diversity in ecological communities. University of Chicago Press, Chicago.

Segura, A., C. Kruk, D. Calliari, F. García-Rodriguez, D. Conde, C. E. Widdicombe, and H. Fort. 2013. Competition drives clumpy species coexistence in estuarine phytoplankton. Scientific Reports 3:1037.

Servais, T., O. Lehnert, J. Li, G. L. Mullins, A. Munnecke, A. Nützel, and M. Vecoli. 2008. The Ordovician biodiversification: revolution in the oceanic trophic chain. Lethaia 41:99-109.

Servais, T., A. W. Owen, D. A. T. Harper, B. Kröger, and A. Munnecke. 2010. The great Ordovician biodiversification event (GOBE): the palaeoecological dimension. Palaeogeography, Palaeoclimatology, Palaeoecology 294:99-119.

Smith, S. L., M. Pahlow, A. Merico, and K. W. Wirtz. 2011. Optimalitybased modeling of planktonic organisms. Limnology and Oceanography 56:2080-2094.

Stomp, M., J. Huisman, G. G. Mittelbach, E. Litchman, and C. A. Klausmeier. 2011. Large-scale biodiversity patterns in freshwater phytoplankton. Ecology 92:2096-2107.

Tappan, H., and A. R. Loeblich Jr. 1973. Evolution of the oceanic plankton. Earth-Science Reviews 9:207-240.

Tilman, D. 1982, Resource competition and community structure: monographs in population biology. Princeton University Press, Princeton, NJ.

Tilman, D., and S. Pacala. 1993. The maintenance of species richness in plant communities. Pages 13-25 in R. E. Rickleffs and D. Schluter, eds. Species diversity in ecological communities. University of Chicago Press, Chicago.

Vallina, S. M., M. Follows, S. Dutkiewicz, J. M. Montoya, P. Cermeno, and M. Loreau. 2014. Global relationship between phytoplankton diversity and productivity in the ocean. Nature Communications 5:4299.

Vecoli, M., and A. Le Hérissé. 2004. Biostratigraphy, taxonomic diversity and patterns of morphological evolution of Ordovician acritarchs (organic-walled microphytoplankton) from the northern Gondwana margin in relation to palaeoclimatic and palaeogeographic changes. Earth-Science Reviews 67:267-311.

Verdy, A., M. Follows, and G. Flierl. 2009. Optimal phytoplankton cell size in an allometric model. Marine Ecology Progress Series 379:1-12.

Vergnon, R., N. K. Dulvy, and R. P. Freckleton. 2009. Niches versus neutrality: uncovering the drivers of diversity in a species-rich community. Ecology Letters 12:1079-1090.

Waide, R. B., M. R. Willig, C. F. Steiner, G. Mittelbach, L. Gough, S. I. Dodson, G. P. Juday, et al. 1999. The relationship between productivity and species richness. Annual Review of Ecology and Systematics 30:257-300.

White, J. W., A. Rassweiler, J. F. Samhouri, A. C. Stier, and C. White. 2014. Ecologists should not use statistical significance tests to interpret simulation model results. Oikos 123:385-388.

Wirtz, K. W. 2011. Non-uniform scaling in phytoplankton growth rate due to intracellular light and $\mathrm{CO}_{2}$ decline. Journal of Plankton Research 33:1325-1341.

Wright, D. H. 1983. Species-energy theory: an extension of speciesarea theory. Oikos 41:496-506.

Yoshida, T., L. E. Jones, S. P. Ellner, G. F. Fussmann, and N. G. Hairston. 2003. Rapid evolution drives ecological dynamics in a predator-prey system. Nature 424:303-306.

Zobel, M., and M. Pärtel. 2008. What determines the relationship between plant diversity and habitat productivity? Global Ecology and Biogeography 17:679-684.

\section{References Cited Only in the Online Appendixes}

Alimov, A. F. 2001. Studies on biodiversity in the plankton, benthos, and fish communities, and the ecosystems of fresh water bodies differing in productivity. Biology Bulletin 28:75-83.

Barnett, A. J., K. Finlay, and B. E. Beisner. 2007. Functional diversity of crustacean zooplankton communities: towards a trait-based classification. Freshwater Biology 52:796-813.

Beardall, J., D. Allen, J. Bragg, Z. V. Finkel, K. J. Flynn, A. Quigg, T. A. V. Rees, A. Richardson, and J. A. Raven. 2009. Allometry and stoichiometry of unicellular, clonal and multicellular phytoplankton. New Phytologist 181:295-309.

Beaver, J. R., and T. L. Crisman. 1989. Analysis of the community structure of planktonic ciliated protozoa relative to trophic state in Florida lakes. Hydrobiologia 174:177-184.

Bec, B., Y. Collos, A. Vaquer, D. Mouillot, and P. Souchu. 2008. Growth rate peaks at intermediate cell size in marine photosynthetic picoeukaryotes. Limnology and Oceanography 53:863-867.

Biggs, B. J. F., and R. A. Smith. 2002. Taxonomic richness of stream benthic algae: effects of flood disturbance and nutrients. Limnology and Oceanography 47:1175-1186.

Bogdan, K. G., and J. J. Gilbert. 1984. Body size and food size in freshwater zooplankton. Proceedings of the National Academies of Sciences of the USA 81:6427-6431.

Chen, X., G. Chen, H. Lu, X. Liu, and H. Zhang. 2015. Long-term diatom biodiversity responses to productivity in lakes of Fuxian and Dianchi. Biodiversity Science 23:89-100.

Conkright, M. E., W. W. Gregg, and S. Levitus. 2000. Seasonal cycle of phosphate in the open ocean. Deep-Sea Research 47:159175.

Das, B., R. Nordin, and A. Mazumder. 2008. Relationship between phytoplankton paleoproduction and diversity in contrasting trophic states. Aquatic Ecosystem Health and Management 11:78-90.

Delgado-Molina, J. A., P. Carrillo, J. M. Medina-Sánchez, M. VillarArgaiz, and F. J. Bullejos. 2009. Interactive effects of phosphorus loads and ambient ultraviolet radiation on the algal community in a high-mountain lake. Journal of Plankton Research 31:619-634.

Dieckmann, U., and R. Law. 1996. The dynamical theory of coevolution: a derivation from stochastic ecological processes. Iournal of Mathematical Biology 34:579-612.

Dieckmann, U., P. Marrow, and R. Law. 1995. Evolutionary cycling in predator-prey interactions: population dynamics and the red queen. Journal of Theoretical Biology 176:91-102.

Dodson, S. 1991. Species richness of crustacean zooplankton in European lakes of different sizes. International Association of Theoretical and Applied Limnology Proceedings 24:1223-1229.

- 1992. Predicting crustacean zooplankton species richness. Limnology and Oceanography 37:848-856.

Dodson, S. I., S. E. Arnott, and K. L. Cottingham. 2000. The relationship in lake communities between primary productivity and species richness. Ecology 81:2662-2679.

Doebeli, M., and U. Dieckmann. 2000. Evolutionary branching and sympatric speciation caused by different types of ecological interactions. American Naturalist 156(suppl):S77-S101.

Dolan, J. R., R. Lemée, S. Gasparini, L. Mousseau, and C. Heyndrickx. 2006. Probing diversity in the plankton: using patterns in tintinnids (planktonic marine ciliates) to identify mechanisms. Hydrobiologia 555:143-157.

Droop, M. R. 1973. Some thoughts on nutrient limitation in algae. Journal of Phycology 9:264-272. 
Eloranta, P. 1986. Phytoplankton structure in different lake types in central Finland. Holarctic Ecology 9:214-224.

. 1995. Phytoplankton of the national park lakes in central and southern Finland. Annales Botanici Fennici 32:193-209.

Froelich, P. N., M. L. Bender, N. A. Luedtke, G. R. Heath, and T. DeVries. 1982. The marine phosphorus cycle. American Journal of Science 282:474-511.

Grover, J. P., D. L. Roelke, and B. W. Brooks. 2012. Modeling of plankton community dynamics characterized by algal toxicity and allelopathy: a focus on historical Prymnesium parvum blooms in a Texas reservoir. Ecological Modelling 227:147-161.

Hansen, B., P. K. Bjørnsen, and P. J. Hansen. 1994. The size ratio between planktonic predators and their prey. Limnology and Oceanography 39:395-403.

Hessen, D. O., B. A. Faafeng, V. H. Smith, V. Bakkestuen, and B. Walsdeng. 2006. Extrinsic and intrinsic controls of zooplankton diversity in lakes. Ecology 87:433-443.

Hoffmann, M. D., and S. I. Dodson. 2005. Land use, primary productivity, and lake area as descriptors of zooplankton diversity. Ecology 86:255-261.

Irigoien, X., J. Huisman, and R. P. Harris. 2004. Global biodiversity patterns of marine phytoplankton and zooplankton. Nature 429: 863-867.

Jones, L. E., and S. P. Ellner. 2007. Effects of rapid prey evolution on predator-prey cycles. Journal of Mathematical Biology 55:541-573.

Korhonen, J. J., J. Wang, and J. Soininen. 2011. Productivity-diversity relationships in lake plankton communities. PLoS ONE 6:e22041.

Leibold, M. A. 1999. Biodiversity and nutrient enrichment in pond plankton communities. Evolutionary Ecology Research 1:73-95.

Litchman, E., C. A. Klausmeier, O. M. Schofield, and P. G. Falkowski. 2007. The role of functional traits and trade-offs in structuring phytoplankton communities: scaling from cellular to ecosystem level. Ecology Letters 10:1170-1181.

Marinone, M. C., S. M. Marque, D. A. Suárez, M. D. C. Dieguez, P. Prez, P. D. L. Ríos, D. Soto, and H. E. Zagarese. 2006. UV radiation as a potential driving force for zooplankton community structure in Patagonian lakes. Photochemistry and Photobiology 82:962-971.

Mittelbach, G. G., C. F. Steiner, S. M. Scheiner, K. L. Gross, H. L. Reynolds, R. B. Waide, M. R. Willig, S. I. Dodson, and L. Gough. 2001. What is the observed relationship between species richness and productivity? Ecology 82:2381-2396.

Montoya, J. P., M. Voss, and D. G. Capone. 2007. Spatial variation in N2-fixation rate and diazotroph activity in the tropical Atlantic. Biogeosciences 4:369-376.

Mougi, A., and Y. Iwasa. 2011. Unique coevolutionary dynamics in a predator-prey system. Journal of Theoretical Biology 277:83-89.

Nielsen, S. L. 2006. Size-dependent growth rates in eukaryotic and prokaryotic algae exemplified by green algae and cyanobacteria: comparisons between unicells and colonial growth forms. Lournal of Plankton Research 28:489-498.

Nwadiaro, C. 1990. A hydrobiological survey of the Chanomi creek system, lower Niger Delta, Nigeria. Limnologica 21:263-274.

Ogawa, Y., and S. E. Ichimura. 1984. Phytoplankton diversity in inland waters of different trophic status. Japanese Journal of Limnology 45: 173-177.

Patalas, K. 1971. Crustacean plankton communities in forty-five lakes in the Experimental Lakes Area, northwestern Ontario. $\underline{\text { Journal of }}$ the Fisheries Board of Canada 28:231-244.

Raven, J. A. 1998. The twelfth Tansley lecture-small is beautiful: the picophytoplankton. Functional Ecology 12:503-513.

Rossetti, G., P. Viaroli, and I. Ferrari. 2009. Role of abiotic and biotic factors in structuring the metazoan plankton community in a lowland river. River Research and Applications 25:814-835.

Sieburth, J. M., V. Smetacek, and J. Lenz. 1978. Pelagic ecosystem structure: heterotrophic compartments of the plankton and their relationship to plankton size fractions. Limnology and Oceanography 23:1256-1263.

Soininen, J., and S. Meier. 2014. Phytoplankton richness is related to nutrient availability, not to pool size, in a subarctic rock pool system. Hydrobiologia 740:137-145.

Stomp, M., J. Huisman, G. G. Mittelbach, E. Litchman, and C. A. Klausmeier. 2011. Large-scale biodiversity patterns in freshwater phytoplankton. Ecology 92:2096-2107.

Uku, J. N., and K. M. Mavuti. 1994. Comparative limnology, speciesdiversity and biomass relationship of zooplankton and phytoplankton in 5 fresh-water lakes in Kenya. Hydrobiologia 272:251-258.

Verdy, A., M. Follows, and G. Flierl. 2009. Optimal phytoplankton cell size in an allometric model. Marine Ecology Progress Series 379:112.

Waide, R., M. Willig, C. Steiner, G. Mittelbach, L. Gough, S. Dodson, G. Juday, and R. Parmenter. 1999. The relationship between productivity and species richness. Annual Review of Ecology and Systematics 1999:257-300.

Walsby, A. E., and D. P. Holland. 2006. Sinking velocities of phytoplankton measured on a stable density gradient by laser scanning. Journal of the Roval Society Interface 3:429-439.

Weckström, K., A. Korhola, and J. Weckström. 2007. Impacts of eutrophication on diatom life forms and species richness in coastal waters of the Baltic Sea. Ambio 36:155-160.

Whitesid, M., and R. Harmswor. 1967. Species diversity in chydorid (Cladocera) communities. Ecology 48:664-667.

Associate Editor: Egbert H. van Nes Editor: Judith L. Bronstein 